\title{
Pathomicrobial studies on Salmonella Gallinarum infection in broiler chickens
}

\author{
Divya Kumari, S.K. Mishra and Deepika Lather \\ Department of Veterinary Pathology, College of Veterinary Science, \\ Lala Lajpat Rai University of Veterinary and Animal Sciences, Hisar, Haryana 125 001, India \\ Corresponding author: Divya Kumari, email: divyasworld19@gmail.com \\ Received: 02-05-2013, Revised: 17-06-2013, Accepted: 17-06-2013, Published online: 08-08-2013
}

doi: $10.14202 /$ vetworld.2013.725-729

How to cite this article: Kumari D, Mishra SK and Lather D (2013) Pathomicrobial studies on Salmonella Gallinarum infection in broiler chickens, Veterinary World 6(10): 725-729.

\begin{abstract}
Aim: To conduct detailed pathomicrobial studies on Salmonella Gallinarum infection in broiler chickens.

Materials and Methods: Bacteriological and pathological studies were conducted on 134 dead poultry birds collected from 23 different farms suspected to be infected with $S$. Gallinarum.

Results: Mortality pattern revealed that maximum mortality occurred in 1-2 week aged birds. Out of 23 Salmonella isolates, 19 samples were identified as $S$. Gallinarum $(9,12)$ and 4 samples as Salmonella Enteritidis $(9,12$ : gm). Isolates were found to be most sensitive to Polymyxin B (100\%). The present study also showed re-emergence of chloramphenicol sensitivity $(83.33 \%)$. Pathological lesions observed were bronze discolouration of liver, splenomegaly and necrotic foci on liver, spleen and heart. Microscopically, liver and spleen revealed aggregation of heterophils, lymphocytes and macrophages, nonsuppurative myocarditis, fibrinous pericarditis, interstitial nephritis, necrotic enteritis and serofibrinous pneumonia.

Conclusion: It was concluded that $S$. Gallinarum 9, 12 was the main serotype causing Salmonellosis in poultry birds. Polymyxin B was the most sensitive drug (100\%) for Salmonella infection along with re-emergence of chloramphenicol sensitivity for Salmonella (83.33\%) infection.
\end{abstract}

Key words: broiler, drug sensitivity, pathology, Salmonella Gallinarum

\section{I ntroduction}

Fowl typhoid, an acute septicaemic disease of avian species that is caused by Salmonella Gallinarum [1] affects all age groups of chickens. Morbidity is high among all age groups of the birds, whereas mortality may range widely from $10 \%$ to $90 \%$ [2]. Maintaining a disease free status is a challenging exercise due to the rapid expanding nature of the industry. This is indicated by the fact that a number of Salmonella outbreaks reported in the world are a result of injudicious introduction of infected birds [3]. Thus, poultry industry is facing great setbacks due to frequent outbreaks of salmonellosis [4]. Since its discovery, many efforts have been made to control and prevent the occurrence in commercial poultry farming. However, outbreaks of Salmonellosis still remain a serious economic problem in countries where control measures are not efficient or in those areas where the climatic conditions favour the environmental spread of these microbes [5]. The economic losses are chiefly due to morbidity, mortality, reduced growth rate, reduced feed conversion efficiency, drop in egg production, decreased fertility and hatchability [6]. The endemicity of the disease has been established in India including Haryana where the infection was first detected in Gurgaon area in 1981

Copyright: The authors. This article is an open access article licensed under the terms of the Creative Commons Attribution License (http://creativecommons.org/licenses/by/2.0) which permits unrestricted use, distribution and reproduction in any medium, provided the work is properly cited.
[7]. Mahajan et al. [8] studied major diseases affecting broiler chickens during 1987-1990 in Haryana and observed that fowl typhoid was the one that caused maximum mortality $(10.54 \%)$ and accounted for the second highest number of outbreaks (198) after E. coli (266). Control of fowl typhoid is difficult [9] due to endemicity of the disease, facultative intracellular nature of causative organism, both vertical [10] and horizontal [11] modes of transmission, presence of carrier stage and multiple drug resistance. The widespread and indiscriminate use of antibiotics in the treatment of poultry diseases has lead to an increase in the number of resistant Salmonella strains isolated [12]. Antimicrobial resistance is a global public health concern [13].

Thus, the present study aimed to evaluate the pathological and bacteriological findings of fowl typhoid and to understand their antibiogram.

\section{Materials and Methods}

Postmortem examination was conducted on 134 dead poultry carcasses received from 23 different farms and were divided into three groups on the basis of their age i.e. Group I (0-1 wks), Group II (1-2 wks) and Group III (2-3 wks) to study the mortality pattern. The study was conducted in the Department of Veterinary Pathology, College of Veterinary Science, Lala Lajpat Rai University of Veterinary and Animal Sciences, Hisar, Haryana. Gross pathological changes like swollen, congested liver with bronze discoloration, 
Table-1. In-vitro chemotherapeutic drug sensitivity (\% sensitivity) of Salmonella spp. isolated from visceral organs and heart blood

\begin{tabular}{lc}
\hline Drug & \% sensitivity to Salmonella spp. \\
\hline Amikacin & 83.33 \\
Ampicillin & 75.00 \\
Amoxycillin & 91.66 \\
Cefixime & 83.33 \\
Chloramphenicol & 83.33 \\
Doxycycline Hydrochloride & 91.66 \\
Ciprofloxacin & 66.66 \\
Furoxone & 83.33 \\
Cefoperazone & 75.00 \\
Colistin & 83.33 \\
Co-Trimoxazole & 75.00 \\
Enrofloxacin & 91.66 \\
Gentamycin & 66.66 \\
Amoxycillin \& Sulbactam & 91.66 \\
Nalidixic acid & 16.66 \\
Amoxyclav & 75.00 \\
Ofloxacin & 75.00 \\
Polymyxin B & 100 \\
Streptomycin & 75.00 \\
Oxytetracycline & 83.33 \\
\hline
\end{tabular}

enlarged spleen, multiple necrotic foci on spleen and liver; and multiple white nodules on heart with distortion in shape suggest that carcass can be suspected to be infected with Salmonella Gallinarum. Clinical signs and history regarding vaccination was collected from owners which showed that infected birds exhibited acute illness, ruffled feathers, inappetance, difficulty in breathing, reluctance to move and watery to mucoid yellowish diarrhoea which further confirms our assumption of Salmonellla Gallinarum infection. The birds were vaccinated against Marek's disease (on 0 day), Newcastle disease (at 5 days and 22 days) and Infectious bursal disease (at 14 days) and were maintained under standard managemental practices.

During postmortem examination, blood from the hearts of carcasses was collected with help of sterilized syringes for bacteriological examination. Different organs were examined critically for gross lesions and were collected under aseptic conditions for bacteriological isolations. Tissue pieces of heart, liver, lung, spleen, intestine, pancreas, proventriculus, bursa of fabricius and kidney were collected in a 10\% buffered formalin for histopathological examination.

I solation and characterization: Heart blood and tissue samples collected aseptically were inoculated in Rappaport enrichment medium and incubated at $43^{\circ} \mathrm{C}$ for 24 hours. After 24 hours, inoculation was done on MacConkey's Lactose agar (MLA), Brilliant Green agar (BGA), Salmonella Shigella Agar (SSA) and Xylose Lysine Deoxycholate agar (XLD). Primary identification of the growth was done by colony morphology and Gram's staining. The pure cultures were subjected to various biochemical tests for further characterization [14]. Isolates were subjected to invitro drug sensitivity test using 20 antimicrobials by the disc diffusion method as suggested by Bauer et al. [15].

Serotyping of the isolates: Organisms positive for Salmonella spp. were sent to National Salmonella and Escherichia Centre (NSEC), Central Research
Institute, Kasauli, Himachal Pradesh, India for further serotyping.

Pathological findings: All the organs and tissues of the carcasses were examined critically for gross changes during postmortem examination and the lesions observed were recorded. The formalin fixed tissues were processed and stained using routine haematoxylin and eosin staining method [16].

\section{Results and Discussion}

Mortality pattern: Age-wise mortality due to Salmonella spp. revealed maximum mortality in group II followed by group I (Fig. 1). These results are in agreement with previous reports [17]. It is likely due to the fact that chicks are not fully immunocompetent when they are below 2 weeks of age because of a lower percentage of CD4+CD8 - in the thymus; CD4-CD8+ and $\mathrm{CD} 4+\mathrm{CD} 8+$ in the spleen [18] as well as due to absence of protection from maternal antibodies at 1-2 weeks of age.

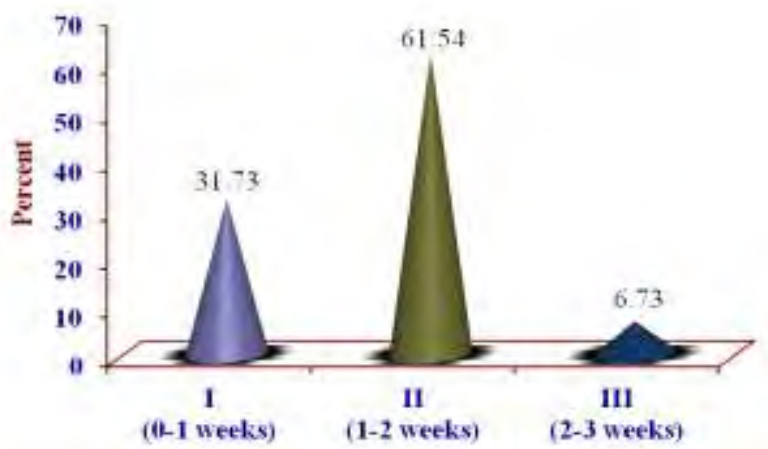

Figure-1. Age-wise distribution of mortality (\%) in poultry due to Salmonella infection

Salmonella characterization: Out of 23 Salmonella isolates sent for serotyping, 19 samples were identified as Salmonella Gallinarum $(9,12)$ and 4 samples as Salmonella Enteritidis (9,12: gm). Salmonella Gallinarum and Salmonella Enteritidis share a common immunodominant surface antigen (O9), such 


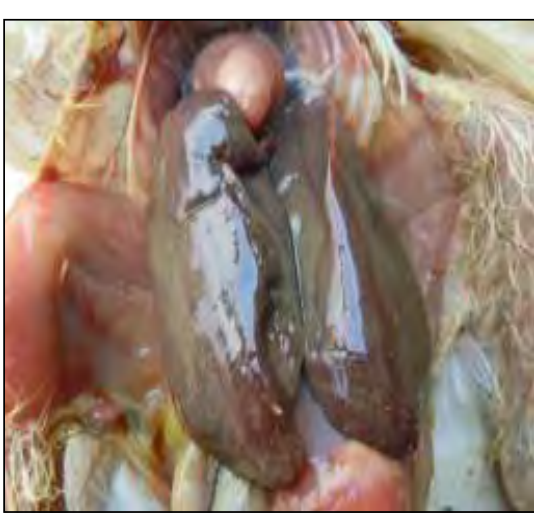

Figure-2. Bronze discoloration with enlargement of liver (Salmonella Gallinarum infection)

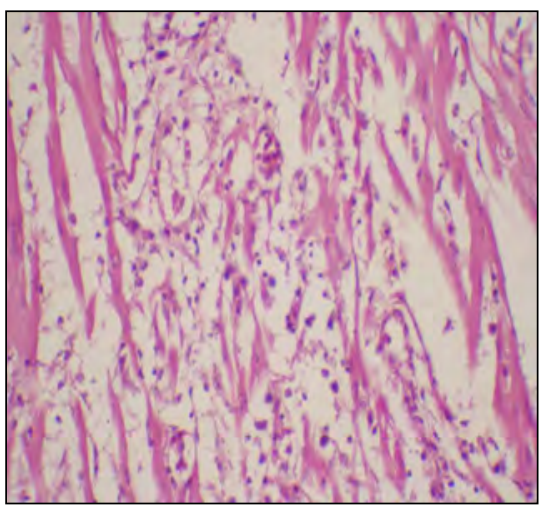

Figure-5. Heart: Severe myocarditis with fragmented myocardial muscle fibres along with infiltration of lymphocytes and heterophils (Salmonella Gallinarum infection)H \& E x 33

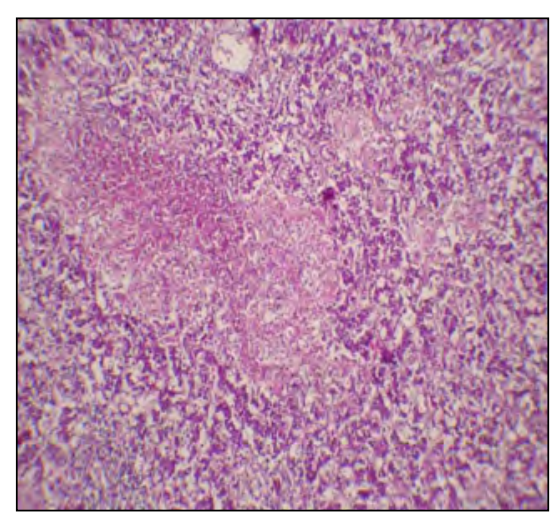

Figure-3. Liver: Showing large area of coagulative necrosis, surrounded by leucocytes. (Salmonella Gallinarum infection) H \& E x 33

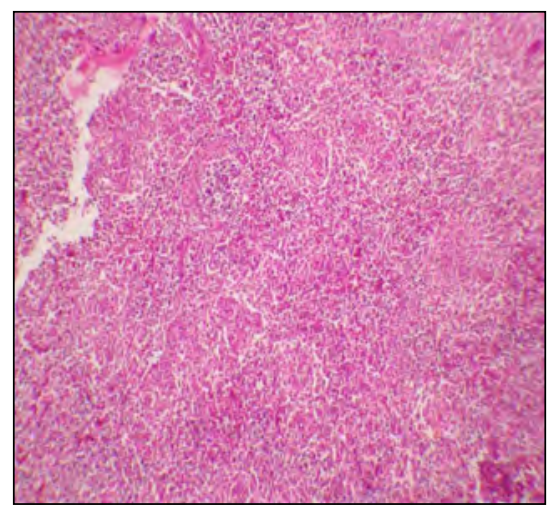

Figure-6. Spleen: Showing secondary follicles and multiple necrotic areas (Salmonella Gallinarum infection) $H \& E \times 33$

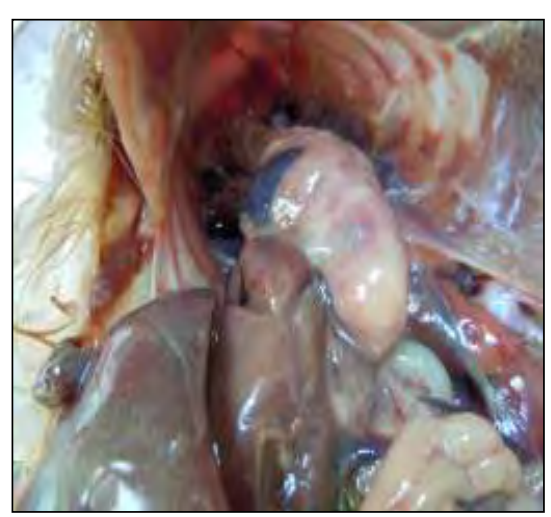

Figure-4. Necrotic nodule on heart (Salmonella Gallinarum infection)

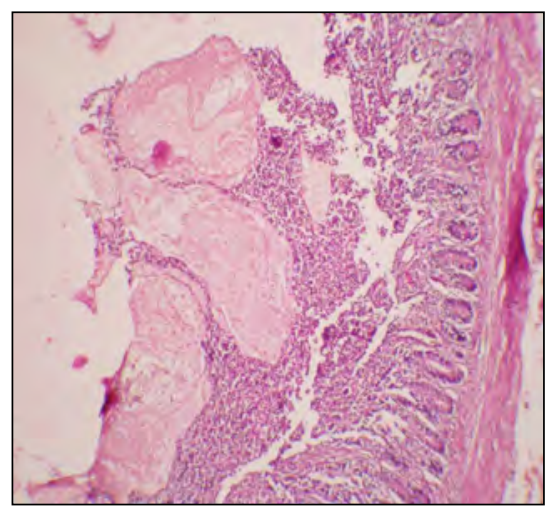

Figure-7. Intestine: Necrotic enteritis characterized by presence of necrotic mass along with desquamated epithelial cells and leucocytes in the lumen (Salmonella Gallinarum infection) $H \& E \times 33$ that $S$. Enteritidis preinfected poultry were protected against colonization with Salmonella Gallinarum. This shows that coexistence of $S$. Gallinarum and $S$. Enteritidis in poultry prompts competition as a result of the shared immunodominant O9-antigen which generates cross-immunity [19]. Several published studies in other countries have reported antimicrobial resistance in Salmonella [20-22]. Antibiogram patterns of isolates in the present investigation showed varying degree of sensitivity to the chemotherapeutic agents tested (Table-1). Salmonella spp. were found to be most sensitive to polymyxin B $(100 \%)$ which was in agreement with the findings of Kavitha et al. [23] followed by amoxicillin, amoxicillin sublactam, enrofloxacin, doxycycline hydrochloride (91.66\%). In our study, Salmonella spp. was found to be resistant to nalidixic acid (84\%). The Salmonella isolates in India from 1996-99 and 2001 were reported to be $100 \%$ chloramphenical sensitive and sensitivity of $79 \%$ was also reported in 2000 [24]. The present study also observed chloramphenical sensitivity of around 83.33\%; similar findings have been reported by Taddele et al. [25]. This re-emergence of chloramphenicol sensitivity could be attributed to the limited use of this antimicrobial during the last decade in India [26]. Highest sensitivity of Salmonella to polymyxin B might be due to the cationic action of polymyxin $B$ on cell membrane of susceptible bacteria where it causes bleb formation on cell wall and morphological changes in the cytoplasm [27]. The varying degree of resistance and sensitivity to chemotherapeutic drugs has also been reported by Sujatha et al. [28]. High prevalence of nalidixic acid resistance among Salmonella Gallinarum was also reported by previous workers [25]. In the present study, the resistance to above mentioned antibiotics might be attributed mainly to the frequent and indiscriminate use of these antibiotics for treatment, prophylaxis and as feed supplements.

Pathological studies: During necropsy examination carcasses of the Salmonella infected birds appeared jaundiced.

Liver: Grossly, the liver appeared swollen, congested along with bronze discoloration (Fig.2). Microscopically, hepatitis characterized by leucocytic infiltration at perivascular areas along with hydropic vacuolation in hepatocytes, multiple necrotic foci was noticed with Kupffer cell hyperplasia. Few areas displayed necrosis of hepatocytes, with focal aggregation of heterophils, lymphocytes and macrophages (Fig.3). Similar degenerative, necrotic and infiltrative lesions have been reported earlier [28-30].

Heart: The cardiac lesions consisted of mild to moderate congestion and hemorrhage. In few cases, multiple white nodules with distorted shapes were observed on the heart (Fig.4). Histopathologically 
severe degeneration and fragmentation of myocardial muscle fibres (non suppurative myocarditis) was observed in most of the cases with leucocytic infiltration (Fig.5). Fibrinous pericarditis with infiltration of heterophils, lymphocytes and macrophages was also observed in some cases. Similar findings have been reported by Msoffe et al., [31].

Spleen: There was splenomegaly along with multiple necrotic foci on the surface. Microscopically, there was severe depletion of lymphoid cells in white pulp along with reticuloendothelial cell hyperplasia (Fig.6). Besides this in a few cases, a number of secondary lymphoid follicles was noticed. Similar histopathological changes including focal necrosis, reticulo endothelial cell hyperplasia and secondary lymphoid follicles have been reported by Shivaprasad [30].

Intestine: Grossly, catarrhal enteritis was evident in some cases characterized by thick slimy mucus exudate on mucosal surfaces in the lumen of intestine. Histopathologically there was desquamation of mucosal epithelium resulting in denuded villi and lumen was filled with necrotic mass (Fig.7). Secretory glands were atrophied at some places due to severe infiltration of heterophils and mononuclear cells. Goblet cell hyperplasia and focal fibroblastic connective tissue proliferation between the glands was present in many cases. Giannella [32] reported that Salmonella induced diarrhoea is multifactorial. The onset of fluid secretion is preceded by a massive influx of inflammatory cells leading to release of prostaglandins that stimulate intestinal adenylcyclase mediated fluid secretion.

Pancreas: In pancreas, there was mild congestion and hemorrhages along with mild degenerative changes. Leucocytic infiltration in acinar cells and interlobular connective tissue was present in most of the cases. The histopathological changes in affected birds were in congruence with the observations of Prasanna et al. [29].

Lungs: Lungs were highly congested with pneumonic lesions in most of the cases. Microscopically moderate congestion and hemorrhages were observed with presence of RBCs in the alveoli (red hepatization). At places, there was presence of serofibrinous exudate in alveoli and interlobular septa. Similar lesions have been reported by Shivprasad [30].

Kidneys: Grossly, kidneys were enlarged with prominent lobulation and necrotic foci on the surface. Microscopically, glomeruli were contracted alongwith degenerative changes in the renal tubular epithelium. Similar degenerative and infiltrative changes in kidneys of birds affected with fowl typhoid have been described by Shivaprasad [30].

Bursa of fabricius: Grossly, only mild congestion was observed in bursa of Fabricius. Histopathological changes include mild depletion of lymphoid tissue in bursal follicles along with interfollicular fibrosis. Loss of lymphoid tissue from follicles and degeneration of bursa of fabricius has been reported by Garren and Barber [33]. These workers suggested that changes in bursa resulted from adverse physiological conditions like anorexia, dehydration, anaemia etc.

Poventriculus: The proventriculitis was characterized by congestion, mucosal degeneration along with infiltration of heterophils and lymphocytes in mucosa extending up to serosal layer in some cases. Mucosal glands were atrophied due to leucocytic infiltration in a few cases. There was degeneration of proventricular glands and lumen was filled with detached epithelial mass. The microscopic changes in proventriculus were similar to those reported by Rao et al. [34].

\section{Conclusion}

S. Gallinarum 9, 12 was mainly involved in causing Salmonellosis in poultry birds tested in the present study. In some of the cases $S$. Enteritidis was also isolated. Polymyxin B was the most sensitive drug (100\%) for treating Salmonella infections. Surprisingly, our study also revealed that Salmonella infections are also highly sensitive to chloramphenicol .

\section{Recommendations for farm owners}

Because polymyxin B was found to be the most sensitive drug for Salmonella infection in the present study, we recommend the drug for treatment of salmonellosis.

\section{Authors' contributions}

DK and SKM participated in the preparation of experimental design and the facilities of the research, drafted the manuscript. DL revised the final draft of manuscript. All authors read the final manuscript.

\section{Acknowledgements}

The authors express their gratitude to the Dean, College of Veterinary Science, Lala Lajpat Rai University of Veterinary and Animal Sciences, Hissar, Haryana for providing the facilities and fund for conducting this experiment.

\section{Competing interests}

The authors declare that they have no competing interests.

\section{References}

1. Priyantha, M.A.R (2012) An Overview: Vaccination to control fowl typhoid in Commercial layers, Sri Lanka. Wayamba Journal of Animal Science, Pp.- 23-25.

2. Latife Beyaz, Ayhan Atasver, Fuat Aydin, K. Semih Gumssoy and Secil Abay (2010) Pathological and clinical findings and tissue distribution of Salmonella Gallinarum infection in turkey poults. Turk. J. Vet. Anim. Sci., 34(2): 101110 .

3. Meeusen, E.N.T., Waker, J., Peter, A., Pastoret, P.P. and Jungersen, G. (2007) Current status of Veterinary vaccine. Clinical Microbiology Review. Pp.-489-510.

4. Fatma, A.G., El-Gohary, A.H., El-Bably, M.A. and Mohamed, A.A. (2012). Vitro antibiotic sensitivity of isolated strains of salmonella and E. coli from poultry farm. 
Compandium of 7th Int. Sci. Conf., Mansoura, 28-30 August. Pp.- 191-199.

5. Barrow, P.A. and Freitas Neto, O.C. (2011) Pullorum disease and fowl typhoid--new thoughts on old diseases: a review. Avian Pathol. 40 (1): 1-13.

6. Mamta, S.K. Mishra, and Deepika Lather (2010) Ameliorating effect of tulsi (ocimum sanctum) leaf powder on pathology of salmonella gallinarum infection in broiler chickens. Haryana Vet. 49: 6-10.

7. Anon (1980-81) Annual progress report of disease investigation laboratory, Gurgaon, Department of Veterinary Public Health and Epidemiology, Haryana Agricultural University, Hisar.

8. Mahajan, N.K., Jindal, N. and Kulshrestha, R.C. (1994) Major broiler diseases in some parts of Haryana. Indian J. Anim. Sci. 64: 1118-1122.

9. Soncine, R.A. and Back, A. (2001) Salmonella Enteritidis em aves: erradicação ou controle por vacinação. In: Conferência Apinco de Ciência e Tecnologia Avícolas, Campinas. Anais, São Paulo: FACTA, 1: 21-30.

10. Paiva, J.B., Penha, F., Anguello, Y.M.S., Siva, M.D., Gardin, Y., Resende, F., Berchieri, A. and Sestsi, L. (2009) Efficacy of several Salmonella vaccination programme against experimental challenge with Salmonella Gallinarum in commercial brown breeder hens. Brazilian Journal of Poultry Science, 11(1): 65-72.

11. Cox, N.A., Bailey, J.S. and Berrang, M.E. (1996) Extent of Salmonellae contamination in breeder hatcheries, Poultry Science, Champaign, 70: 416-418.

12. Enabulele, S.A., Amune, P.O. and Aborisade, W.T. (2010) Antibiograms of Salmonella isolates from poultry in Ovia North East local government area Edo State, Nigeria. Agric. Biol. J. North Am., 1(6): 1287-1290.

13. Ahmed, M.M., Rahman, M.M., Mahbub, K.R. and Wahiduzzaman, M. (2011) Characterization of antibiotic resistant Salmonella spp isolated from chicken eggs of Dhaka city. J. Sci. Res., 3: 191-196.

14. Carter, G.R. (1984) Diagnostic procedures in Veterinary Bacteriology and Mycology, $4^{\text {th }}$ edn. Charles C. Thomas, Springfield, Illinois, U.S.A.

15. Bauer, A.W., Kirby, W.M.M., Sherris, J.C. and Truck, M. (1966) Antibiotic susceptibility testing by standardizing single disc method. Am. J. Clin. Path. 45: 493.

16. Luna L.G. (1968) Manual of histologic staining methods of the Armed forces Institute of Pathology. $3^{\text {rd }}$ edn. Mc Graw hill Book Company, New York.33-37.

17. Kumar, T., Mahajan, N.K. and Rakha, N.K. (2010) Epidemiology of fowl typhoid in Haryana, India. World Poultry Science Journal. 66: 503-510.

18. Erf, G.F, Walter G Bottje, Tina K Bersi (1998) CD4, CD8 and TCR defined T-cell subsets in thymus and spleen of 2- and 7week old commercial broiler chickens, Vet Immunol Immunopatho, 62(4): 339-348.

19. Lee, Y.J., Kang, M.S., Woo, Y.K., Mo, I.P. and Tak, R.B. (2001) Competitive exclusion against Salmonella Gallinarum of Salmonella Enteritidis infected chickens.
Journal of Veterinary Sciences. 2(1): 33-36.

20. Pokharel P, Rai SK, Karki G, Katuwal A, Vitrakoti R. and Shrestha SK (2009) Study of enteric fever and antibogram of Salmonella isolates at a teaching hospital in Kathmandu Valley. Nepal Med. Coll. J., 11(3): 176-178.

21. Wei, L.S. and Wee, W. (2011) Antibiogram and heavy metal resistance pattern of Salmonella spp. Isolated from wild Asian Sea Bass (Lates calcalifer) from Tok Bali, Kelantan, Malaysia. Jordan J. Biological Sci., 4(3): 125-128.

22. Selvaraj, R., Das, R., Ganguly, S., Ganguli, M., Dhanalakshmi, S. and Mukhopadhayay, S.K. (2010) Characterization and antibiogram of Salmonella spp. from poultry specimens. J. Microbiol. Antimicrobials, 2(9): 123-126.

23. Kavitha, R., Chaturvedi, V.K. and Pandey, K.D. (2008) Plasmid profile of Salmonella Weltevereden isolates of lizard and goat origin. Journal of Veterinary Public Health, 6(2): 117-120.

24. Mandal, S., Mandal, M.D. and Pal, N.K. (2004) Reduced minimum inhibitory concentration of chloramphenicol for Salmonella enterica serovar typhi. Indian J. Med. Sci., 58: 16-23.

25. Taddele, M.H., Rathore, R. and Dhama, K. (2012) Antibiogram assay of Salmonella Gallinarum and other Salmonella enteric serovars of poultry origin in India. Asian J. of Animal and Veterinary Advances. 7(4): 309-317.

26. Mohanty, S., K., Renuka., Sood. S., Das, B.K. and Kapil, A. (2006) Antibiogram pattern and seasonality of Salmonella serotypes in north Indian tertiary care hospital. Epidemiol. Infect., 134:961-966.

27. Daugelavicius, R., Bakiene, E. and Bamford, D.H. (2000) Stages of polymyxin B interaction with $E$. coli cell envelope. Antimicrobial agents and chemotherapy. 44(11): 2969.

28. Sujatha, K., Dhanalakshmi, K. and Rao, A.S. (2003) Isolation and characterization of Salmonella Gallinarum from chicken. Indian Vet. J. 80: 473-474.

29. Prasanna, K., Somvanshi, R. and Paliwal, O.P. (2001) Experimental fowl typhoid and pullorum disease infection in chicken: Histopathological and ultrastructural studies of small intestine and liver. Indian J. Vet. Path. 21: 18-20.

30. Shivprasad, H L. (2000) Fowl typhoid and Pullorum disease. SciTech. Rev. 19: 405-424.

31. Msoffe, P.L.M., Minga, U.M., Mtambo, M.M.A., Gwakisa, P.S. and Olsen, J.E. (2006) Differences in resistance to Salmonella enterica serovar Gallinarum infection among indigenous local chicken ecotypes in Tanzania. Avian Pathol. 35(4): 270-276.

32. Giannella, R.A. (1979) Importance of intestinal inflammatory reaction in Salmonella- mediated intestinal secretion. Infect. Immun. 23: 140-145.

33. Garren, H.W. and Barber, C.W. (1955) Endocrine and lymphatic glands changes occurring in young chickens with fowl typhoid. Poult. Sci. 34: 1250-1258.

34. Rao, S.B.V., Naraya, D.R., Ramnani and Das, J. (1952) Avian salmonellosis: Studies on Salmonella Gallinarum. Indian J. Vet. Sci. 22: 199-208. 